1 ANALYTICAL SCIENCE

7 \& TECHNOLOGY

Vol. 26, No. 6, 375-380, 2013

http://dx.doi.org/10.5806/AST.2013.26.6.375

\title{
Analysis of germanium in rock and sediment by ICP/MS after ammonium bifluoride $\left(\mathrm{NH}_{4} \mathrm{HF}_{2}\right)$ digestion
}

\author{
Chul Hun Eum ${ }^{\star}$ and Won Myung Choi
}

Geochemical Analysis Center, Korea Institute of Geoscience and Mineral Resources, Daejeon 305-350, Korea (Received November 8, 2013; Revised November 26, 2013; Accepted November 26, 2013)

\section{이플루오린화 암모늄 시료분해 및 ICP/MS에 의한 암석 및 퇴적물 중 게르마늄 분석 \\ 음철헌 ` 최원명 \\ 한국지질자원연구원 지질자원분석실 \\ (2013. 11. 8. 접수, 2013. 11. 26. 수정, 2013. 11. 26. 승인)}

\begin{abstract}
Ammonium biflouride $\left(\mathrm{NH}_{4} \mathrm{HF}_{2}\right)$ digestion was studied for germanium analysis in rock and sediment by inductively coupled plasma mass spectrometry (ICP/MS). QLO-1 and SDO-1 are used for reference materials from USGS. Sediment, basalt and ball clay for GeoPT were chosen as real samples. The loss of germanium in open vessel digestion was well known which can be caused by easy transformation to volatile compounds. But ammonium bifluoride digestion could suppress loss of germanium in open vessel digestion. Germanium recovery was not influenced by hydrogen peroxide with ammonium bifluoride digestion. Furthermore, the new method was simple and rapid in germanium analysis by ICP/MS. MDL(method detection limit) was $0.015 \mu \mathrm{g} /$ $\mathrm{g}$ and germanium recovery was $106 \sim 128 \%$.

요 약: 본 연구에서는 암석과 퇴적물 시료를 대상으로 이플루오린화 암모늄을 이용한 시료 분해법을 적 용하여 open vessel digestion 후 유도결합 플라즈마 질량분석법(Inductively coupled plasma mass spectrometry, ICP/MS)으로 게르마늄을 분석하였다. 미국 지질조사소 표준물질 중 QLO-1, SDO-1을 사용 하였고, 실제 시료로 GeoPT용 퇴적물, 현무암, 점토를 사용하였다. 휘발하여 손실되기 쉬운 것으로 알려 진 게르마늄을 이플루오린화 암모늄 $\left(\mathrm{NH}_{4} \mathrm{HF}_{2}\right)$ 시료 분해법을 사용함으로서 게르마늄 휘발 억제와 동시 에 암석 및 퇴적물을 open vessel digestion하에서 간단하고 빠르게 분해 가능하였으며, 또한 이플루오린 화 암모늄 분해법에 과산화수소를 함께 사용해도 게르마늄의 회수율에 영향을 끼치지 않았다. ICP/MS에 의한 게르마늄 분석 결과, MDL (method detection limit)은 $0.015 \mu \mathrm{g} / \mathrm{g}$, 게르마늄 회수율은 $106 ~ 128 \%$ 이었다.
\end{abstract}

Key words: germanium analysis, ammonium bifluoride, rock and sediment, open vessel digestion, ICP/MS

Corresponding author

Phone : +82-(0)42-868-3675 Fax : +82-(0)42-868-3393

E-mail : cheum@kigam.re.kr 


\section{1. 서 론}

게르마늄 $(\mathrm{Ge})$ 은 광섬유 산업이나 적외선 광학, 고 분자 중합 촉매, 태양 전지 등 다양하게 이용되고 있는 원소이다. 이로 인해 그 사용량이 점차 증가하 지만 지구상의 함량은 원소들 중 53 번째의 약 1.5 $\mu \mathrm{g} / \mathrm{mL}$ 로 매우 낮은 농도로 존재한다. ${ }^{1}$ 이렇게 미량 으로 존재하는 게르마늄을 분석하기 위해서는 높은 감도를 가지는 분석법이 필요하고 이를 위해 게르마 늄을 수소화합물 형태로 바꾸어 기기로 도입 함으로 서 검출한계를 낮출 수 있는 수소화합물 생성법 (hydride generation, $\mathrm{HG}$ )을 이용하는 분석방법들이 보고되어 있다. Casstillo 등은 ${ }^{2}$ 게르마늄 함량이 약 $100 \mu \mathrm{g} / \mathrm{mL}$ 인 coal ash를 불산-염산으로 용해 한 후 아세트 산과 아세트산 이온의 완충 용액으로 처리하 여 수소화합물 발생법-원자흡광기(HG-AAS)로 분석 하였으며, Halicz는 ${ }^{3}$ 규산염 광물 중의 게르마늄을 불산-질산-인산의 혼합산으로 용해시켜 수소화합물 발생법-원자흡광기(HG-AAS)로 분석하였다. 또한 NaKahara 등은 ${ }^{4}$ iron meteorites를 질산과 마이크로 고주파 용해 장치로 전처리 후 수소화합물 발생법유도결합 플라즈마 원자방출 분광기(HG-ICP-OES) 로 게르마늄을 분석하였다. 이처럼 수소화합물 생성 법은 기압식 분무 시료 도입법보다 이론적으로 수십 에서 수백배 낮은 검출한계를 가지기 때문에 미량으 로 존재하는 게르마늄을 분석하는데 효과적이다. 그 러나 수소화합물을 생성하는 반응을 위해 사용되는 환원제와 보조산의 농도를 최적화해야 하고, 수소화 합물을 형성할 때 시료 내 공존하는 원소들에 대한 간섭현상이 존재하는 것이 알려져 있으며, ${ }^{5-6}$ 이는 특히, 공존하는 원소들이 전이원소들일 경우 간섭현 상이 더 커진다는 것이 알려져 있다..$^{79}$ 이를 해결하 기 위해 예비 환원시약을 이용하거나 산의 농도를 증가시켜 전이원소들의 용해도를 증가 시켜 간섭현 상을 억제할 수 있다고 보고되어 있으나 ${ }^{7-11}$ 이는 실 제 매트릭스를 알 수 없는 미지시료를 분석하기 위 해 수소화합물 생성 최적화에 까다로운 요인으로 작 용할 수 있다.

$\mathrm{ICP} / \mathrm{MS}$ 또한 높은 감도와 정확성, 정밀성으로 인 하여 지질학적 시료 내 미량원소 분석에 널리 사용 되는 분석법이다. ${ }^{12-14}$ 그러나 $\mathrm{ICP} / \mathrm{MS}$ 의 시료 도입장 치가 기압식 분무 시료 도입방식이기 때문에 분석하 고자 하는 시료는 반드시 액체 상태로 존재하여야 하며, 이를 위해 고체상태의 지질학적 시료는 산 또
는 융제를 이용하여 투명용액의 상태로 만들어 분석하 여야 한다. 따라서 시료를 전처리하는 과정은 $\mathrm{ICP} / \mathrm{MS}$ 을 이용하기 위해 대단히 중요한 과정이며, 특히 게 르마늄과 같이 전처리 하는 과정에서 쉽게 휘발될 수 있는 원소를 분석하기 위해서는 그에 적합한 전 처리 과정이 필요하다. 게르마늄은 $\mathrm{GeH}_{4}\left(-88.1{ }^{\circ} \mathrm{C}\right)$, $\mathrm{GeF}_{4}\left(-36.5^{\circ} \mathrm{C}\right), \mathrm{GeCl}_{4}\left(83.1^{\circ} \mathrm{C}\right)$ 의 형태로 휘발될 수 있다고 알려져 있는데, ${ }^{1}$ 이는 open vessel digestion system 하에서 그 손실이 크며 특히 염산을 사용하 거나 또는 많은 양의 황화물 또는 염화물을 포함한 시료에서 더 잘 일어나는 것으로 알려져 있다. ${ }^{3,15-16}$ 특히 Davidson 등은 open vessel digestion system 하에서 염산을 사용하지 않고 질산-불산-과염소산을 이용하여 시료를 녹이는 경우에도 약 $70 \%$ 의 게르마 늄 손실이 일어나는 것을 보고하였다. ${ }^{17}$ 때문에 게르 마늄을 위한 전처리 방법에는 closed vessel digestion system이 제안되고 있다. ${ }^{3-16}$ 그러나 이와 달리 Shin 등은 open vessel digestion system 하에서 불산-질 산-인산으로 암석 및 퇴적물 시료를 완전 용해하여 수소화합물 발생법-유도결합플라스마 원자방출분광 기(HG-ICP-OES)로 게르마늄을 분석하였다. Closed vessel digestion system인 마이크로파 분해 장치에 서 불산-질산을 사용하여 같은 시료를 처리하여 비 교한 결과 인산을 사용함으로서 open vessel digestion system에서도 게르마늄의 손실을 효과적 으로 억제하는 것으로 나타났다. ${ }^{18}$ 그러나 위 방법 을 사용할 경우 시료 매질로 소량의 인산이 잔류하 게 되며, 이는 시료가 잘 녹지 않아 과량의 불산-질 산-인산 혼합 산을 사용 했을 때 잔류한 인산의 높 은 점도로 인해 $\mathrm{ICP} / \mathrm{MS}$ 로 직접 분석하기에는 물리 적 방해가 존재 할 수 있다. 최근 Zhang, W. 등이 이플루오린화암모늄 $\left(\mathrm{NH}_{4} \mathrm{HF}_{2}\right)$ 을 이용한 open vessel digestion system을 이용하여 암석시료의 용해방법 을 보고 하였다. ${ }^{19}$ 이 방법은 암석시료를 대상으로 이플루오린화암모늄과 질산만을 이용하여 시료 내 포함된 지르콘과 같은 내화성 물질까지 효과적으로 녹일 수 있다는 것을 보여주었다. 본 연구에서는 위 방법이 염산을 사용하지 않고, 뚜껑이 있는 바이알 을 이용하여 닫힌 상태에서 시료를 이플루오린화암 모늄과 반응시키는 과정이 포함되어있다는 것에 주 목하여 시료 전처리 과정에서 일어나는 게르마늄의 휘발을 막고, 암석과 퇴적물을 투명용액으로 녹여 이를 유도결합 질량분석기로 분석하는 방법을 연구 하고자 하였다. 


\section{2. 실 험}

\section{1. 시료 및 시약}

시료분해에 사용된 이플루오린화암모늄(>97\%, SamJung, Korea)은 적외선 램프와 PFA 병을 사용한 정제기를 이용, $140 ~ 150{ }^{\circ} \mathrm{C}$ 의 온도에서 정제하여 사 용하였다. 실험에 사용된 모든 질산은 전자급 질산을 한번 더 정제한 2회 정제된 질산(ASP, Korea)을 사용 하였으며, $36 \%$ 과산화수소(Junsei, Japan)를 사용하였 고, 물은 탈이온수 제조기(Milli-Q, USA)로 얻어진 초 순수 $(18 \mathrm{M} \Omega)$ 를 사용하였다. 표준물질은 미국지질조 사소(United States Geological Survey, USGS)의 QLO1 (quartz latite), SDO-1 (Devonian Ohio shale)을 사용하였 고 실제 시료로 퇴적물(green river sediment), 현무암 (basalt), 진훍(ball clay)을 사용하였다. 검정곡선 작성을 위한 표준용액은 $10 \mu \mathrm{g} / \mathrm{mL}$ 게르마늄 용액(Accustandard, USA)을 단계별로 묽혀, 각각 $0.1,0.5,1.0,5.0 \mu \mathrm{g} / \mathrm{L}$ 로 만들어 사용하였다. 내부표준물질로 사용된 $1000 \mu \mathrm{g} /$ $\mathrm{mL}$ 로듐(Rh) 표준용액(Accustandard, USA)은 $100 \mu \mathrm{g} /$ $\mathrm{L}$ 로 묽혀 사용하였다.

\section{2. 시료 전처리}

시료 분해 시 사용된 뚜껑이 달린 PFA 바이알은 $25 \mathrm{~mL}$ 용량을 사용하였으며(savillex, USA), 전기로 (Lindberg, USA) 및 바이알 크기에 맞춰 제작된 블록 히터(ASP, Korea)를 사용하였다.

2.2.1. 이플루오린화암모늄 시료 전처리법 $\left(\mathrm{NH}_{4} \mathrm{HF}_{2}\right.$ $\mathrm{HNO}_{3}$ )

오븐에서 2 시간 동안 건조시킨 후 데시케이터에서 충분히 식힌 시료 $0.1 \mathrm{~g}$ 과 정제된 이플루오린화암모늄 을 $0.4 \mathrm{~g}$ 취해 $\mathrm{PFA}$ 병에 넣고 뚜껑을 닫는다. 뚜껑이 닫힌 $\mathrm{PFA}$ 병을 $240{ }^{\circ} \mathrm{C}$ 의 온도로 3 시간 동안 전기로 에서 가열한 후 시료를 식힌다. PFA 병의 뚜껑을 열 고 $2 \mathrm{~mL}$ 의 질산을 가한 후 다시 뚜껑을 닫고 가열 판에서 $160{ }^{\circ} \mathrm{C}$ 의 온도로 한 시간 동안 가열한다. $\mathrm{PFA}$ 병을 식힌 후 뚜껑을 열고, 다시 가열판에서 $160{ }^{\circ} \mathrm{C}$ 의 온도로 가열하여 건고 시킨다. 건고 된 시 료에 질산 $1 \mathrm{~mL}$ 와 $100 \mu \mathrm{g} / \mathrm{mL}$ 농도의 로듐 내부표 준물질 $1 \mathrm{~mL}$ 를 넣고 $\mathrm{PFA}$ 병의 뚜껑을 초순수 $3 \mathrm{~mL}$ 로 세 번 씻어 PFA병에 담아 PFA병의 뚜껑을 닫은 후, 용액이 투명해 질 때까지 가열판에서 $120^{\circ} \mathrm{C}$ 로 가열한다. 투명해진 용액을 $100 \mathrm{~mL}$ 부피 플라스크 에 옮겨 눈금을 맞춘다.
Table 1. Condition and parameters used for ICP/MS analysis

\begin{tabular}{ll}
\hline \hline ICP/MS spectrometer & PerKinElmer DRC II \\
RF power & $1,250 \mathrm{~W}$ \\
Plasma Ar gas flow & $18 \mathrm{Lmin}^{-1}$ \\
Auxiliary Ar gas flow & $1.2 \mathrm{Lmin}^{-1}$ \\
Nebulizer Ar gas flow & $0.9 \mathrm{Lmin}^{-1}$ \\
Nebulizer & Meinhard type(quartz) \\
Spray chamber & Cyclonic \\
Interface cones & Platinum \\
Lens voltage & $8 \mathrm{~V}$ \\
Dwell time & $50 \mathrm{~ms}$ \\
Replicate & 3 \\
Detector mode & Dual \\
Isotope monitored & ${ }^{74} \mathrm{Ge}$ \\
\hline
\end{tabular}

2.2.2. 과산화수소를 함께 사용한 전처리법 $\left(\mathrm{NH}_{4} \mathrm{HF}_{2}\right.$ $\mathrm{HNO}_{3}-\mathrm{H}_{2} \mathrm{O}_{2}$ )

과산화수소 또한 강한 산화력으로 분해 과정에서 사용되는 시약이다. ${ }^{21}$ 위 2.2.1.의 과정에서 바이알의 뚜껑을 열고 $160{ }^{\circ} \mathrm{C}$ 에서 시료를 건고시키는 과정에 과산화수소를 3 방울 첨가하였으며 다른 과정은 모두 동일하였다.

\section{3. 기기 및 측정조건}

$\mathrm{ICP} / \mathrm{MS}$ 는 PerkinElmer사의 것을 사용하였으며, 분 석 전 최적화 과정을 통하여 $\mathrm{Ce} / \mathrm{CeO}<0.03, \mathrm{Ba} / \mathrm{Ba}++$ $<0.03$ 이하의 조건에서 실험을 수행하였다. $\mathrm{ICP} / \mathrm{MS}$ 를 위한 분석 조건은 Table 1 과 같다.

\section{3. 결과 및 고찰}

\section{1. 이플루오린화암모늄 시료 분해 $\left(\mathrm{NH}_{4} \mathrm{HF}_{2}-\mathrm{HNO}_{3}\right)$ 후 $\mathrm{ICP} / \mathrm{MS}$ 에 의한 표준물질 내 게르마늄 측정 결과}

$\mathrm{ICP} / \mathrm{MS}$ 로 게르마늄을 분석하기 위해 가장 중요한 것은 게르마늄의 휘발을 억제하고 시료를 투명용액으 로 만드는 것이다. 게르마늄은 시료 분해 시 염산 $(\mathrm{HCl})$ 을 사용할 경우 특히 심각한 휘발 손실이 일어난 다는 것은 잘 알려진 사실이다. ${ }^{11,15}$ 또한 염산을 사용 하지 않는 경우에도 시료 내 황화물과 염화물이 공존 할 때 open digestion system 하에서는 게르마늄이 쉽 게 휘발될 수 있으며 게르마늄 농도가 $100 \mu \mathrm{g} / \mathrm{g}$ 이하 일 경우 무기산으로 시료를 분해하는 과정에서도 손 실이 있을 수 있다는 것이 보고되어 있다. ${ }^{16}$ 이로 인 
해 게르마늄 분석을 위한 시료 분해에는 closed vessel digestion이 제안되고 있다. 대표적인 closed vessel digestion 방법인 고압 산 분해법은 분해법 전용 용기 인 bomb 등에 고압을 가하여 시료를 빠른 시간 안에 효과적으로 분해할 수 있지만, 이는 고압에서 사용 가 능한 bomb 수의 제한과 압력을 가하는 분해 장치가 수용할 수 있는 bomb 수의 제한, 그리고 밀폐된 bomb에 가해지는 높은 압력에 따른 안전문제를 수반 한다. 이플루오린화 암모늄 분해법은 이와 달리 밀폐 된 상태에서 이플루오린화 암모늄과 시료를 반응시킨 후, open vessel digestion 의 장점인 블록 히터 또는 일반적인 가열판으로 시료를 다량으로 분해할 수 있 으며 밀폐되지 않은 상태로 시료를 건고시키는 open vessel digestion 이다. 또한 시료에 대한 분해력과 분 해 최적화를 위한 온도 및 시료와 이플루오린화암모 늄의 양 등도 Zhang, W. 등에 의해 지르코늄 $(\mathrm{Zr})$ 과 하 프늄(Hf)을 대상으로 이미 보고 된 바 있다. ${ }^{19}$ 이 분해 법의 게르마늄 분석 적합성을 시험하기 위해 USGS 표준물질 중 게르마늄에 비하여 염소와 황의 농도가 높은 것을 선택하였으며, 세부정보를 Table 2에 나타 내었다. 선택한 두 표준물질을 이플루오린화암모늄 시 료 분해법으로 녹인 후 $\mathrm{ICP} / \mathrm{MS}$ 로 분석하였고 분석한 결과는 Table 3 과 같다.

Table 3에서 나타낸 바와 같이 MDL은 $0.015 \mu \mathrm{g} /$ $\mathrm{mL}$ 로 나타났으며 측정된 $\mathrm{RSD}$ 는 $3.1 \sim 3.2 \%$ 였다. 본 연구에서 가장 중요한 것은 open vessel digestion 후 게르마늄의 손실이 없어야 하는 점이다. 위에서 언급 한 것과 같이 게르마늄은 open vessel digestion 시 쉽게

Table 2. Certified values of reference materials

\begin{tabular}{ccccc}
\hline \hline \multirow{2}{*}{ CRM } & \multicolumn{4}{c}{ Concentration } \\
\cline { 2 - 5 } & Chlorine & Sulfur & Germanium & Carbon $^{\text {a) }}$ \\
\hline QLO-1 & $220 \mu \mathrm{g} / \mathrm{g}$ & $30 \mu \mathrm{g} / \mathrm{g}$ & $1.3 \mu \mathrm{g} / \mathrm{g}$ & - \\
SDO-1 & - & $5.35 \mathrm{wt} \%$ & $1.3 \mu \mathrm{g} / \mathrm{g}$ & $9.95 \mathrm{wt} \%$ \\
\hline
\end{tabular}

a) Total carbon concentration

Table 3. Analysis results of germanium in CRMs by ICP/MS after $\mathrm{NH}_{4} \mathrm{HF}_{2}-\mathrm{HNO}_{3}$ sample digestion $(\mathrm{n}=3)$

\begin{tabular}{cccccc}
\hline \hline CRM & $\begin{array}{c}\left.\text { MDL }^{a}\right) \\
(\mu \mathrm{g} / \mathrm{g})\end{array}$ & $\begin{array}{c}\text { Ref. } \\
\text { value } \\
(\mu \mathrm{g} / \mathrm{g})\end{array}$ & $\begin{array}{c}\text { Exp. } \\
\text { value } \\
(\mu \mathrm{g} / \mathrm{g})\end{array}$ & $\begin{array}{c}\text { RSD } \\
(\%)\end{array}$ & $\begin{array}{c}\text { Recovery } \\
(\%)\end{array}$ \\
\hline QLO-1 & \multirow{2}{*}{0.015} & 1.3 & 1.38 & 3.23 & 106 \\
SDO-1 & & 1.3 & 1.59 & 3.12 & 122 \\
\hline
\end{tabular}

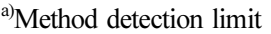

1) $\mathrm{GeO}_{2}+\mathrm{NH}_{4} \mathrm{~F}^{126^{\circ} \mathrm{C}} \rightarrow\left(\mathrm{NH}_{4}\right)_{2} \mathrm{GeF}_{6} \cdot n \mathrm{NH}_{4} \mathrm{~F}^{170^{\circ} \mathrm{C}}\left(\mathrm{NH}_{4}\right)_{2} \mathrm{GeF}_{6} \cdot 2 \mathrm{NH}_{4} \mathrm{~F}$

$$
\stackrel{220^{\circ} \mathrm{C}}{\rightarrow}\left(\mathrm{NH}_{4}\right)_{2} \mathrm{GeF}_{6} \stackrel{282^{\circ} \mathrm{C}}{\rightarrow} \mathrm{NH}_{4} \mathrm{GeF}_{5} \stackrel{341^{\circ} \mathrm{C}}{\rightarrow} \mathrm{GeF}_{4} \stackrel{370^{\circ} \mathrm{C}}{\rightarrow} \mathrm{GeF}_{2}
$$

2) $\mathrm{GeO}_{2}+3 \mathrm{NH}_{4} \mathrm{~F} \cdot \mathrm{HF}=\left(\mathrm{NH}_{4}\right)_{2} \mathrm{GeF}_{6}+\mathrm{NH}_{3}+2 \mathrm{H}_{2} \mathrm{O}$

Fig. 1. Transformation mechanism of germanium with ammonium bifluoride.

휘발 손실 가능하다고 알려져 있지만, 본 실험 결과 훌 륭한 회수율을 얻을 수 있었다. 이것은 이플루오린화암 모늄이 게르마늄과 반응하여 게르마늄 플루오린화암모 늄 화합물(germanium fluoroammonium complexe)을 형 성하는 것으로 설명할 수 있다. ${ }^{20}$ 해당 반응에 대한 메카니즘을 Fig. 1에 나타내었다. Fig. 1의 1)과 같이 게르마늄 산화물 $\left(\mathrm{GeO}_{2}\right)$ 은 플루오린화암모늄과 반응하 여 $220{ }^{\circ} \mathrm{C}$ 이상에서 ammonium hexafluorogermanate $\left(\left(\mathrm{NH}_{4}\right)_{2} \mathrm{GeF}_{6}\right)$ 의 형태로 존재하게 되는데, 이는 또한 Fig. 1의 2)에서 보여지듯 이플루오린화암모늄과의 반 응에도 동일하게 적용된다. 암석 및 퇴적물 내 광물이 완전 분해되지 않으면 잔여물 내부에 게르마늄이 남 아있을 수 있다. 시료의 완전 분해를 위해 밀폐된 상 태에서 이플루오린화암모늄과 시료를 이플루오린화암 모늄의 끓는 점인 $240{ }^{\circ} \mathrm{C}$ 로 반응시켰으며, $240{ }^{\circ} \mathrm{C}$ 의 온도에서 게르마늄과 이플루오린화암모늄의 생성물인 $\left(\mathrm{NH}_{4}\right)_{2} \mathrm{GeF}_{6}$ 가 $280{ }^{\circ} \mathrm{C}$ 이상의 온도에 분해되므로, 시 료 건고 시 가해지는 $160{ }^{\circ} \mathrm{C}$ 의 온도에서의 게르마늄 휘발 손실을 억제하였다고 판단된다.

\section{2. 이플루오린화암모늄 분해법에 과산화수소} 첨가 후 표준물질 내 게르마늄 측정 결과

위에서 실험한 이플루오린화암모늄 시료 분해법은 유기물의 양이 적은 암석 시료 전처리에는 적합하지 만, 많은 양의 유기물을 함유한 시료의 유기물 제거에 는 충분치 않다고 판단되었다. 특히 shale의 경우 그 생성과정이 퇴적물이 오랜 세월을 거쳐 암석으로 변 하는 특성 상 유기물의 함량이 많이 존재하게 된다. 유기물 함량이 $\mathrm{wt} \%$ 로 존재하는 SDO-1의 경우, 이플 루오린화암모늄 시료 분해법으로 시료를 분해했을 때 미세한 부유물이 눈에 보일 정도로 존재하였다. 유기 물이 시료 내 과량으로 존재하면 ICP/MS 측정에 여 러 가지 방해를 일으킬 수 있기 때문에 이것을 제거 할 수 있는 방법을 모색하였다. 게르마늄이 쉽게 휘발 되는 원소로 알려져 있는 만큼 건식 회화법과 같이 높은 온도에서 유기물을 제거하는 것은 적합하지 않 은 방법이므로 낮은 온도에서 사용할 수 있는 유기물 
Table 4. Analysis results of germanium in CRMs by ICP/MS after $\mathrm{NH}_{4} \mathrm{HF}_{2}-\mathrm{HNO}_{3}-\mathrm{H}_{2} \mathrm{O}_{2}$ sample digestion ( $\mathrm{n}=3$ )

\begin{tabular}{cccccc}
\hline \hline CRM & $\begin{array}{c}\text { MDL }^{\text {a) }}(\mu \mathrm{g} / \mathrm{g}) \\
(\mu \mathrm{g} / \mathrm{g})\end{array}$ & $\begin{array}{c}\text { Ref. } \\
\text { value } \\
(\mu \mathrm{g} / \mathrm{g})\end{array}$ & $\begin{array}{c}\text { Exp. } \\
\text { value }\end{array}$ & $\begin{array}{c}\text { RSD } \\
(\%)\end{array}$ & $\begin{array}{c}\text { Recovery } \\
(\%)\end{array}$ \\
\hline QLO-1 & \multirow{2}{*}{0.015} & 1.3 & 1.43 & 2.86 & 110 \\
SDO-1 & & 1.3 & 1.64 & 2.07 & 125 \\
\hline
\end{tabular}

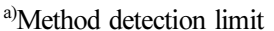

Table 5. Analysis results of Ge in river sediment, basalt, ball clay by ICP/MS ( $\mathrm{n}=3)$

\begin{tabular}{lcccc}
\hline \hline Sample & $\begin{array}{c}\text { Ref. value } \\
(\mu \mathrm{g} / \mathrm{g})\end{array}$ & $\begin{array}{c}\text { Exp. value } \\
(\mu \mathrm{g} / \mathrm{g})\end{array}$ & $\begin{array}{c}\text { RSD } \\
(\%)\end{array}$ & $\begin{array}{c}\text { Recovery } \\
(\%)\end{array}$ \\
\hline Sediment & 1.43 & 1.67 & 1.13 & 119 \\
Basalt & 1.34 & 1.68 & 1.70 & 126 \\
Ball clay & 3.02 & 3.86 & 0.50 & 128 \\
\hline
\end{tabular}

제거 방법 중 질산과 과산화수소를 이용하는 방법을 시험하였다. ${ }^{21}$ 또한 이는 유기물 분해 뿐 아니라 과산화 수소의 산화력으로 인하여 시료에 대한 분해력을 높이 는 효과가 있으므로 이것을 QLO-1과 SDO-1에 사용하 였다. 그 결과 SDO-1의 유기물을 효과적으로 제거할 수 있었으며, 이에 대한 ICP/MS 측정 결과는 Table 4와 같다. $\mathrm{MDL}$ 은 $0.015 \mu \mathrm{g} / \mathrm{mL}$ 로 나타났으며 RSD는 약 $2 \%$ 의 재현성을 가졌다. 실험결과 게르마늄의 회수율은 과산화수소의 첨가에 의한 반응 후 기체를 발생시킴에 도 게르마늄의 회수율이 큰 차이를 보이지 않았다.

3.3. 퇴적암, 현무암, 점토 중 게르마늄 $\mathrm{ICP} / \mathrm{MS}$ 측정 결과

최근 $\mathrm{GeoPT}$ 를 위해 이용된 시료 중 퇴적물(River sediment, GeoPT 31), 현무암(basalt, GeoPT 32), 점토 (ball clay, GeoPT 33)를 대상으로 그 결과값을 비교해 보고자 하였다. 퇴적물과 점토는 $\mathrm{NH}_{4} \mathrm{HF}_{2}-\mathrm{HNO}_{3}-\mathrm{H}_{2} \mathrm{O}_{2}$ 으로 분해하고, 현무암은 $\mathrm{NH}_{4} \mathrm{HF}_{2}-\mathrm{HNO}_{3}$ 로 분해한 뒤 각각의 시료를 $\mathrm{ICP} / \mathrm{MS}$ 로 분석한 게르마늄 분석 결과 는 Table 5와 같다. GeoPT를 통해 각 연구기관의 분 석 보고 결과와 비교한 결과 게르마늄의 회수율은 $119 \sim 128 \%, \mathrm{RSD}$ 는 $0.05 \sim 1.7 \%$ 로 나타났다. 이 결과로 $\mathrm{NH}_{4} \mathrm{HF}_{2}-\mathrm{HNO}_{3}-\mathrm{H}_{2} \mathrm{O}_{2}$ 분해법과, $\mathrm{NH}_{4} \mathrm{HF}_{2}-\mathrm{HNO}_{3}$ 분해법 은 ICP/MS 분석을 위한 시료 중 게르마늄 휘발을 억 제 가능한 분해법 임을 알 수 있었다.

\section{4. 선행 게르마늄 분석 연구들과의 비교}

본 연구의 게르마늄 분석법과 암석 및 퇴적물을 대 상으로 게르마늄을 분석한 선행연구들을 비교하여 Table 6에 나타내었다. 인산을 이용한 open vessel digestion 방법에 비하여 시료 처리 시간이 대단히 짧 았으며, 또한 다른 분석 방법들과는 달리 불산을 사용 하지 않고도 시료를 완전 분해하였다. 이는 마이크로 파 분해법에 비하여 특별한 장치 없이 다량의 시료 처리가 가능한 open vessel digestion method로 적합함 을 알 수 있었다. 또한 수소화물 생성법을 이용한 보 고된 연구들과 같이 좋은 회수율을 나타내었다.

\section{4. 결 론}

시료 분해 시 휘발 손실되는 특성으로 인해 closed vessel digestion 방법이 추천되는 게르마늄의 시료 분 해를 더 빠르고 조작이 간단하며 처리량이 많은 open vessel digestion 방법인 이플루오린화 암모늄 시료 분

Table 6. Comparison between published method and this study for Ge analysis in geological material

\begin{tabular}{|c|c|c|c|c|}
\hline & $\begin{array}{l}\text { This study } \\
\text { ICP-MS }\end{array}$ & $\begin{array}{l}\text { Shin et al. } \\
\text { HG-ICPMS }\end{array}$ & 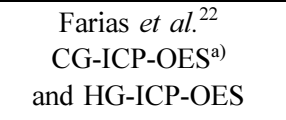 & $\begin{array}{c}\text { ZheMing } \\
\text { et } \text { al. }^{23} \\
\text { CF-HG-ETAAS }^{\text {b) }}\end{array}$ \\
\hline Sample type & rock, clay, sediment & rock, soil, sediment & rock, sediment & soil, sediment \\
\hline Open/close digestion & Open & Open & $\begin{array}{c}\text { Close } \\
\text { (microwave digestion) }\end{array}$ & $\begin{array}{c}\text { Close } \\
\text { (stainless-steel bomb) }\end{array}$ \\
\hline Digestion method & $\begin{array}{c}\mathrm{NH}_{4} \mathrm{HF}_{2}-\mathrm{HNO}_{3} \text { and } \\
\mathrm{NH}_{4} \mathrm{HF}_{2}-\mathrm{HNO}_{3}-\mathrm{H}_{2} \mathrm{O}_{2}\end{array}$ & $\mathrm{HNO}_{3}-\mathrm{HF}-\mathrm{H}_{3} \mathrm{PO}_{4}$ & $\mathrm{HNO}_{3}-\mathrm{HF}$ & $\mathrm{HNO}_{3}-\mathrm{HF}$ \\
\hline Digestion temperature $\left({ }^{\circ} \mathrm{C}\right)$ & 240 & $-{ }^{c)}$ & $-^{c)}$ & 170 \\
\hline Digestion time & $5 \mathrm{~h}$ & $15 \mathrm{~h}$ & $40 \min$ & $7 \mathrm{~h}$ \\
\hline Germanium recovery(\%) & $106 \sim 128$ & $104 \sim 120$ & $94 \sim 130$ & $101 \sim 105$ \\
\hline
\end{tabular}

a)CG-ICP-OES : Chloride generation inductively coupled optical emission spectrometry

${ }^{b}$ CF-HG-ETAAS : Continuous flow hydride generation electrothermal atomic absorption spectrometry

c) not mentioned

Vol. 26, No. 6, 2013 
해법을 이용해 게르마늄의 손실 없이 ICP/MS로 분석 하였다. 이는 closed vessel digestion 방법이 가지고 있 는 밀폐 된 용기 내 고압발생으로 인한 안전 문제 및 다량의 시료 처리의 어려움 등의 문제를 open vessel digestion 방법을 사용 함으로서 극복하였으며, 또한 미지시료의 전이금속 공존으로 인한 까다로운 수소화 물 생성 문제를 불산을 사용하지 않고도 이플루오린 화 암모늄 분해법만으로 암석 및 퇴적물을 완전 분해 후 ICP/MS로 분석 함으로서 간단하고 정확하게 게르 마늄 분석이 가능하였다. 이 방법은 문헌에 보고된 바 와 같이 내화성 물질의 함량이 높은 시료의 분해에도 적합하지만 게르마늄의 휘발을 막는 전처리 방법으로 도 효과적 이었다. 또한 $\mathrm{ICP} / \mathrm{MS}$ 로 측정하는 것이기 때문에 시료만 투명용액으로 만든다면 한번 측정 시 여러 원소를 동시에 정량 할 수 있다는 장점도 가지 고 있다. 게다가 이플루오린화암모늄의 특성 상 불산 $(\mathrm{HF})$ 을 사용하지 않아도 규소의 결합을 깨뜨릴 수 있 기 때문에 이 방법은 quartz latite와 같이 시료 내 규 소 함량이 많은 반도체 중 semiconductor 등에서의 게 르마늄 미량 분석에도 유용하게 이용될 수 있을 것이 라고 사료된다.

\section{감사의 글}

본 연구는 2013년도 한국지질자원연구원의 기본사업 인 시험 분석사업(13-3511-1)의 일환으로 수행되었슴.

\section{참고문헌}

1. N. Greenwood and A. Earnshaw, 'In Chemistry of the elements', Pergamon press: Oxford, U. K. (1984).

2. J. R. Castillo, J. Lanaja and J. Aznare, Analyst, 107, 89-95 (1982)

3. L. Halicz, Analyst, 110, 943-946 (1985).

4. T. Nakahara and T. Wasa, Microchem. J., 49, 202-212 (1994).

5. M. Thompson, B. Pahlavanpour, S. J. Walton and G. G. Kirkbright, Analyst, 103, 705-713 (1978).
6. J. W. Hershey and P. N. Keliher, Spectrochim. Acta Part B, 41(7) 713-723 (1986).

7. B. Welz and M. Melcher, Anal. Chim. Acta, 131, 17-25 (1981).

8. J. Agget and G. Boyes, Analyst, 114, 1159-1161 (1989).

9. A. D'Ulivo, L. Lampugnani and R. Zamboni, Spectrochim. Acta Part B, 47(7), 619-631 (1992).

10. X. P. Yan and Z. M. Ni, Anal. Chim. Acta, 291, 89-105 (1994).

11. I. D. Brindle, X. C. Le and X. F. Li, J. Anal. At. Spectrom., 4, 227-232 (1989).

12. M. Willbold, K. P. Jochum, I. Raczek, M. A. Amini, B. Stoll and A. W. Hofmann, Anal. Bioanal. Chem., 377, 117-125 (2003).

13. X. D. Cao, Y. Chen, Z. M. Gu and X. R. Wang, Intern. J. Environ. Anal. Chem., 76, 295-309 (2000).

14. E. Chajduk, I. Bartosiewicz, M. Pyszynska, J. Chwastowska and H. Polkowska-Motrenko, J. Radioanal. Nucl. Chem., 295, 1913-1919 (2013).

15. R. A. Nadkarni and R. I. Botto, Appl. Spectrosc., 38, 595-598 (1984).

16. U. Husam, E. Abbasi, Ahmet and A. Eroglu, Anal. Sci., 17, 559-560 (2001).

17. R. A. Davidson, D. D. Harbuck and D. D. Hammargren, Atomic Spectrosc., 11, 7-12 (1990).

18. H. S. Shin, M. S. Choi and K. J. Kim, J. Korean. Chem. Soc., 41(8), 399-405 (1997).

19. W. Zhang, Z. C. Hu, Y. S. Liu, H. H. Chen, S. Gao and R. M. Gaschnig, Anal. Chem., 84, 10686-10693 (2012).

20. A. N. D'yachenko and R. I. Kraidenko, Russian Journal of Applied Chemistry, 81, 952-955 (2008).

21. K. E. Jarvis and A. L. Gray, 'Handbook of inductively coupled plasma mass spectrometry', Chapman and Hall, New York, 1992.

22. S. Farias and P. Smichowski, J. Anal. At. Spectrom., 14, 809-814 (1999).

23. N. Zhe-Ming, J. Anal. At. Spectrom., 10, 747-751 (1995). 